\title{
Numerical model of cracking pattern in laminated bamboo specimens under tensile and shear loads
}

\author{
M. Estrada, D. L. Linero, C. Takeuchi \\ Universidad Nacional de Colombia, Facultad de Ingeniería, Colombia \\ mestradam@unal.edu.co,bttps://orcid.org/0000-0002-3089-8857 \\ dllineros@unal.edu.co,https://orcid.org/0000-0001-8198-8839 \\ cptakeucbit@unal.edu.co,bttps://orcid.org/0000-0002-6273-7118
}

ABSTRACT. This work describes a two-dimensional numerical model that allows detecting the appearance of cracks and calculating their propagation in elements made of laminated bamboo, under tension and shear. This composite material has long parallel strong cellulose fibers embedded in a weak lignin matrix. The mechanical models that represents the failure and fracture process of laminated bamboo is still not available in the literature. This numerical model simulates localized strains, showing the beginning and progression of the fracture in the material. The model is based on a twodimensional scheme for plane stresses, using the finite element method. A one-dimensional plasticity constitutive model, based on Weibull probability distribution, is used to describe the mechanical response of the fibers, and a continuum damage constitutive model controls the behavior of the matrix. The homogenization process is done with the rule-of-mixtures, and vanishing fiber diameter simplification. Continuum strong discontinuity approach is employed to detect the jump of the displacement field, during the fracture process. This numerical model is used to simulate the failure of laminated bamboo Guadua angustifolia under tensile and shear tests, which were then compared to experimental data. The results show that the numerical model detects the same crack patterns obtained in tests.

KEYwORDs. Composite material crack; Continuum strong discontinuities; Cracking pattern; Laminated bamboo; Weibull distribution.

\section{OPEN O ACCESS}

Citation: Estrada, M., Linero, D. L., Takeuchi, C., Numerical model of cracking pattern in laminated bamboo specimens under tensile and shear loads, Frattura ed Integrità Strutturale, 48 (2019) 348-356.

Received: 30.10 .2018 Accepted: 15.01.2019 Published: 01.04.2019

Copyright: (C) 2019 This is an open access article under the terms of the CC-BY 4.0, which permits unrestricted use, distribution, and reproduction in any medium, provided the original author and source are credited.

\section{INTRODUCTION}

$\mathrm{I}$ n Colombia there is a species of bamboo called Guadua angustifolia. This is an outstanding species of bamboo in that country, thanks to its physical-mechanical properties, its large size and its constant and abundant use in the construction industry. Guadua angustifolia, commonly called "guadua", is found naturally in Colombia, Ecuador, and 
Venezuela in bamboo forests concentrated in the Andean region [1,2]. Although bamboos have proven to be appropriate materials for the construction of civil structures, their mechanical behavior remains a subject of research. Recently, researchers [3-6] have contributed to determine the mechanical properties, such as stiffness and strenght, of guadua in round and laminated configuration, finding that it has an extraordinary structural performance and great potential in the construction of civil works. Moreover, studies have been carried out on the anatomy and microstructure of different bamboos in the world [7-9] and some specifically on the guadua [10-13]. These latest investigations have revealed that this plant is a composite and functionally graded material.

Despite all efforts to use guadua in the construction of buildings and to investigate its mechanical properties, there are not enough studies about the detailed description of the mechanical behavior of this plant. Consequently, a constitutive model, proposed from a theoretical point of view, that simulates the mechanical behavior of elements and structures manufactured with laminated guadua is presented, taking into account the composite character of this material, without being limited by the geometry, the size or the loads applied. The mechanical behavior of the composite material is determined by the constitutive models of each of its components and by the microstructure of the material, that is, the distribution and orientation of the fibers in the matrix. The constituents, matrix and fibers, are considered isotropic materials, whose behavior is defined by constitutive models of damage and plasticity, respectively.

(a)

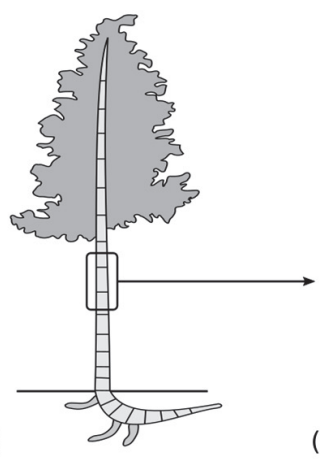

(b)

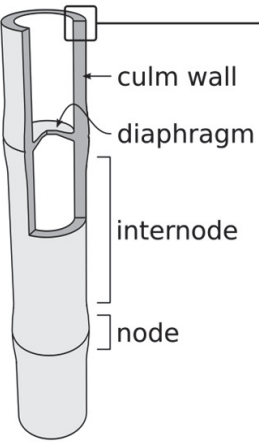

(c)

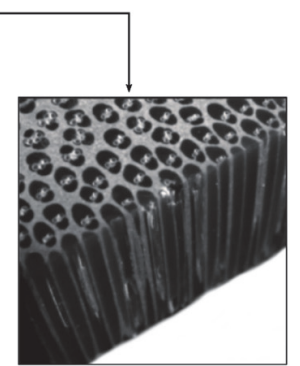

(d)

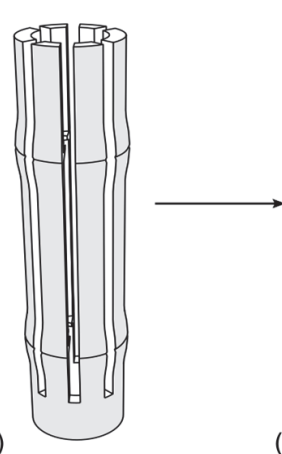

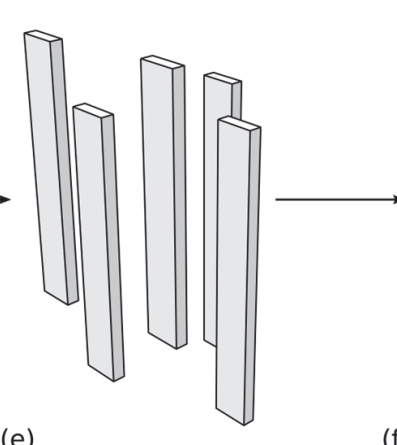

(f)

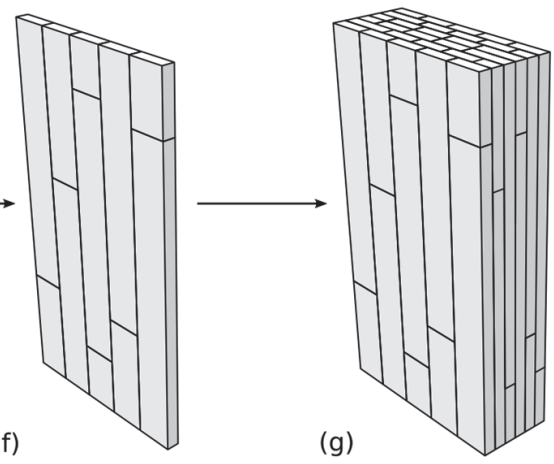

(g)

Figure 1: Round and laminated bamboo: (a) general parts, (b) culm parts, (c) culm wall detail; (d), (e), (f) and (g) lamination process.

\section{MATERIALS: BAMBOO AND LAMINATED BAMBOO}

1 he main parts of the bamboo are the rhizome, the culm (or stem), the branches and the leaves (Fig. 1-a). For practical purposes, the culm is a bar with a circular hollow cross-section, which is divided into the parts indicated in Fig. 1-b. While the bottom parts are especially suitable for the construction, the upper parts of the culm tend to be used for the manufacture of furniture and handicrafts. Figs. 1-b and 1-c show an important characteristic for the formulation of the numerical mechanical model: long fibers are aligned with the longitudinal axis of the culm, which makes it a material reinforced in one direction. Slats with rectangular cross-section are extracted from bamboo culms (Fig. 1-d).

Laminated bamboo is a composite material formed by bamboo slats, which preserve the same orientation fibers and the adherence with each other (Figs. 1-e, 1-f, and 1-g). This material allows to manufacture with prismatic bars with a 
rectangular cross-section or panels of constant thickness. Particularly, the laminated bamboo derived from Guadua Angustifolia is called Laminated Guadua Bamboo (LGB).

\section{METHODS: NUMERICAL MODEL FOR TWO-DIMENSIONAL MEMBERS OF LGB}

7 he proposed numerical model for LGB represents the crack pattern and the mechanical response of twodimensional specimens subjected to static loads, which produce tensile and shear stress [14]. This model assumes perfect adherence among slats and uniform distribution of the fibers into the matrix. The constitutive model of the composite material is derived from the mixing theory [15], the classical constitutive models of two-dimensional damage for matrix [16] and one-dimensional plasticity for the fiber bundle [17,18]. The fracture process is modeled by means of continuum strong discontinuity approach for composite materials reinforced with long fibers $[19,20]$.

\section{Constitutive model for a composite material LGB}

In this model, the behavior of the lignin matrix is represented by a two-dimensional damage constitutive model [16], in which the stress tensor $\boldsymbol{\sigma}^{(m)}$ and the constitutive tangent tensor $\mathbf{C}_{t g}^{(m)}$ are obtained from the strain tensor $\boldsymbol{\varepsilon}^{(m)}$ and the internal variables $r^{(m)}$. In contrast, the behavior of the fiber bundle is described with the one-dimensional plasticity model [17], defined from the proposed progressive failure model [18]. In the fiber bundle constitutive model, the normal stress $\sigma_{s s}^{(f)}$ and the tangent modulus of elasticity $E_{t g}^{(f)}$ are calculated from the longitudinal strain $\varepsilon_{s s}^{(f)}$ and the internal variables $r^{(f)}$, while the strength and stiffness contribution in the transverse direction are neglected.

The constitutive model of the composite material LGB is based on the classical mixing theory for parallel systems and with the negligible fiber diameter simplification [15]. In this model the stress and stiffness are obtained from the weighted sum of its components through its volumetric fractions, while the strain is common for the fibers and the matrix. The strain rate of the matrix $\dot{\boldsymbol{\varepsilon}}^{(m)}$ is equal to that of the composite material, at the same time that the strain rate of the fibers group $\dot{\boldsymbol{\varepsilon}}^{(f)}$ is equal to the strain component of the composite material along the longitudinal direction of fiber $\mathbf{s}$, that is:

$$
\dot{\boldsymbol{\varepsilon}}^{(m)}=\dot{\boldsymbol{\varepsilon}} \quad, \quad \dot{\boldsymbol{\varepsilon}}^{(f)}=\mathbf{s} \cdot \dot{\boldsymbol{\varepsilon}} \cdot \mathbf{s}
$$

The tensor stress rate of LGB is equal to the sum of the products between the volumetric participation coefficients, $k^{(m)}$, and $k^{(f)}$, and the stress rate, $\dot{\sigma}^{(m)}, \dot{\sigma}^{(f)}$ of the matrix $(m)$ and of the fibers $(f)$, respectively, so that:

$$
\dot{\sigma}=k^{(m)} \dot{\boldsymbol{\sigma}}^{(m)}+k^{(f)}(\mathbf{s} \otimes \mathbf{s}) \dot{\sigma}_{s s}^{(f)}
$$

By substituting the constitutive equation of each component in the constitutive equation of LGB, the following expression is obtained for the constitutive tangent tensor of the composite:

$$
\mathbf{C}_{t g}=k^{(m)} \mathbf{C}_{t g}^{(m)}+k^{(f)}(\mathbf{s} \otimes \mathbf{s}) \otimes(\mathbf{s} \otimes \mathbf{s}) E_{t g}^{(f)}
$$

\section{Constitutive model for fibers bundle}

The high dispersion in the mechanical properties of the fibers comes, in part, from measurement errors in the laboratory, but above all, from the natural characteristics of the material. This has been found on different natural fibers, testing by other authors [21-24]. The strength $\sigma_{u}^{(f)}$ of the fibers is related to their volume. When the gauge length of the fiber in tensile tests is constant, it depends only on their cross-section area $a^{(f)}$. Therefore, a modified Weibull probability distribution $[23,25]$ is used to represent the fiber strength of LGB, thus:

$$
P\left(\sigma_{u}^{(f)}, a^{(f)}\right)=1-\exp \left[-\left(\frac{a^{(f)} \sigma_{u}^{(f)}}{a_{0} \beta}\right)^{\alpha}\right]
$$

where $a_{0}$ is the average value of the cross-section area of all the fibers, and the scale parameter $\beta$ is a measure of the characteristic strength of the fibers. The shape parameter $\alpha$ defines the variability of the data. From a progressive failure 
model and the classic uniaxial plasticity model, the following plasticity model is proposed to represent exclusively the mechanical response of the fibers group of LGB.

The axial equilibrium allows establishing that $\sigma_{e f}^{(f)} A_{e f}^{(f)}=\sigma^{(f)} A^{(f)}$, where $\sigma^{(f)}$ and $\sigma_{e f}^{(f)}$ are nominal and effective stress, respectively, and $A^{(f)}$ and $A_{e f}^{(f)}$ are nominal and effective area cross-section, respectively. During the failure process, the effective area of the fiber group is reduced from $A^{(f)}$ to 0 . Consequently, the scalar relation $A_{e f}^{(f)} / A^{(f)}=\sigma^{(f)} / \sigma_{e f}^{(f)}$ is a possible measure of the integrity of the material.

The failure probability of the fibers group $P\left(\sigma_{e f}^{(f)}, a^{(f)}=a_{0}\right)$ is equal to the percentage of fibers whose strength is equal to or less than the effective stress applied to the LGB specimen. That is, the percentage of broken fibers as a function of effective stress indicates the level of material degradation or capacity loss. The failure probability corresponds to:

$$
P\left(\sigma_{u}^{(f)}\right)=1-\frac{A_{e f}^{(f)}}{A^{(f)}} \rightarrow \sigma^{(f)}=\sigma_{e f}^{(f)} \frac{A_{e f}^{(f)}}{A^{(f)}}=\sigma_{e f}^{(f)} \exp \left[-\left(\frac{\sigma_{e f}^{(f)}}{\beta}\right)^{\alpha}\right]=E^{(f)} \mathcal{E}^{(f)} \exp \left[-\left(\frac{\sigma_{e f}^{(f)}}{\beta}\right)^{\alpha}\right]
$$

From the tangent constitutive equation $\dot{\sigma}^{(f)}=E_{t g}^{(f)} \dot{\mathcal{\varepsilon}}^{(f)}$ of LGB, the tangent elasticity modulus $E_{\mathrm{tg}}^{(f)}$ can be obtained as follows.

$$
E_{t g}^{(f)}=\frac{\partial \sigma^{(f)}}{\partial \varepsilon^{(f)}}=E^{(f)} \exp \left[1-\alpha\left(\frac{\sigma_{e f}^{(f)}}{\beta}\right)^{\alpha}\right] \exp \left[-\left(\frac{\sigma_{e f}^{(f)}}{\beta}\right)^{\alpha}\right]
$$

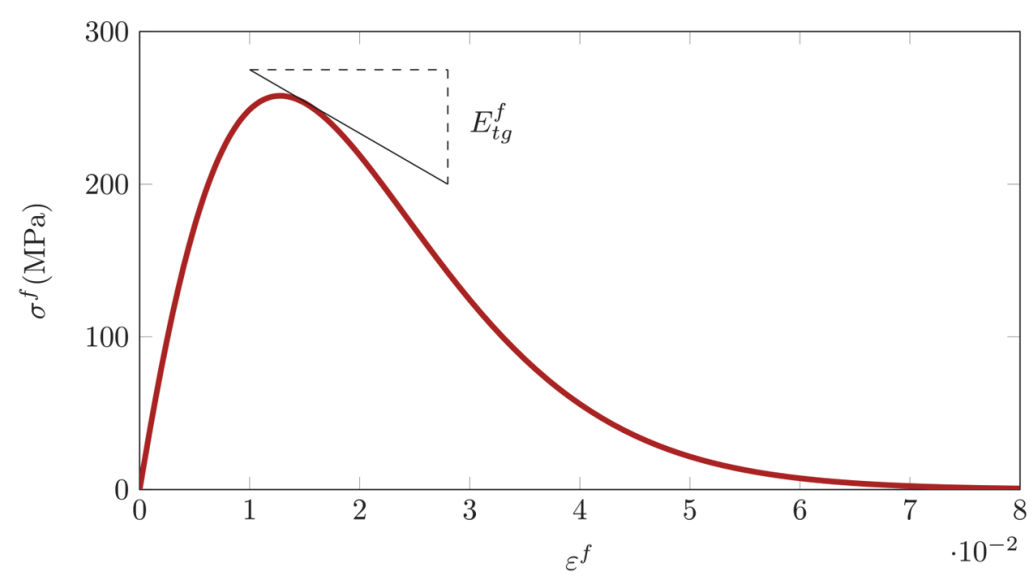

Figure 2: Relationship between the normal stress and longitudinal strain for the fiber bundle.

Substituting of the previous expression into the classical one-dimensional plasticity model, the behavior of the fiber bundle during the stages of inelastic loading can be represented by the softening modulus $H^{(f)}$, which takes the following form:

$$
E_{\text {tg }}^{(f)}=\frac{E^{(f)} H^{(f)}}{E^{(f)}+H^{(f)}} \text {, where } H^{(f)}=\frac{E^{(f)}(1-\alpha \phi)}{\exp (\phi)+\alpha \phi-1} \text { and } \phi=\left(\frac{E^{(f)} \varepsilon^{(f)}}{\beta}\right)^{\alpha}
$$

The Weibull shape and scale parameters, $\alpha$ and $\beta$, come from experimental tensile tests on single fibers. For LGB fibers, these values are $\alpha=1.3236$ and $\beta=678.56 \mathrm{MPa}$. Fig. 2 shows a schematic view of this model.

From the observation of the process of failure of traction and flexion tests in the LGB, it is assumed that the mechanical behavior of the lignin matrix can be represented by a model of continuous damage with differential thresholds of tensile strength and compression $[17,26]$. The continuous damage of the matrix is attributed to the breaking of the polymer chains during the loading process. The code of LGB material constitutive model was written in Fortran 90 and was included into a version of the open-source program COMET. This version allows the no-linear finite element analysis, 
considering the continuum strong discontinuity approach $[19,20]$. The developed program was tested in different simulations.

\section{RESULTS: NUMERICAL SIMULATION OF SPECIMENS SUBJECTED TO TENSION AND SHEAR}

$\mathrm{D}$ ue to the anisotropy of the bamboo culm, its characterization must be done through tests with different configurations. Among all the possibilities, some of them are tensile tests and direct shear tests. The numerical model was tested in these cases to verify the cracking patterns and to adjust some parameters of materials that are difficult to measure in the laboratory. In both tests, the numerical problem is considered as a plane stress problem with its domain discretized into triangular elements. The fiber distribution is considered uniform, so a constant volume fraction of fibers is maintained in all elements of the mesh. The shape and scale Weibull parameters to describe the softening of the fibers were computed from tensile tests of individual vascular bundles of bamboo Guadua angustifolia [27].

\begin{tabular}{rllcccc}
\hline Parameter & Value & Reference & & Parameter & Value & Reference \\
$k^{(m)}$ & 0.60 & & $k^{(f)}$ & 0.40 & \\
$E^{(m)}$ & $500 \mathrm{MPa}$ & {$[28,29]$} & & $E^{(f)}$ & $43 \mathrm{GPa}$ & {$[18,27]$} \\
$v^{(m)}$ & 0.38 & {$[28,29]$} & & $\sigma_{y}^{(f)}$ & $259 \mathrm{MPa}$ & {$[18,27]$} \\
$u^{(m)}$ & $0.20 \mathrm{~N} / \mathrm{mm}$ & {$[30]$} & $G^{(f)}$ & $15.6 \mathrm{GPa}$ & \\
$\sigma_{\max }^{(m)}$ & $5.00 \mathrm{MPa}$ & {$[30]$} & & $\tau_{\max }^{(f)}$ & $130 \mathrm{MPa}$ & \\
\hline
\end{tabular}

Table 1: Material parameters used for the numerical simulations. The exponent $(m)$ or $(f)$ indicates whether it is a property of the matrix or the fibers, respectively.

All material parameters used for the simulations are presented in Tab. 1. The parameter $G^{(f)}$ is obtained from its relation with $E^{(f)}$ and Poisson's ratio, and the maximum shear strength $\tau_{\max }^{(f)}$ is obtained from a transformation of stresses, where $\sigma_{y}^{(f)}$ is taken as the maximum principal stress.

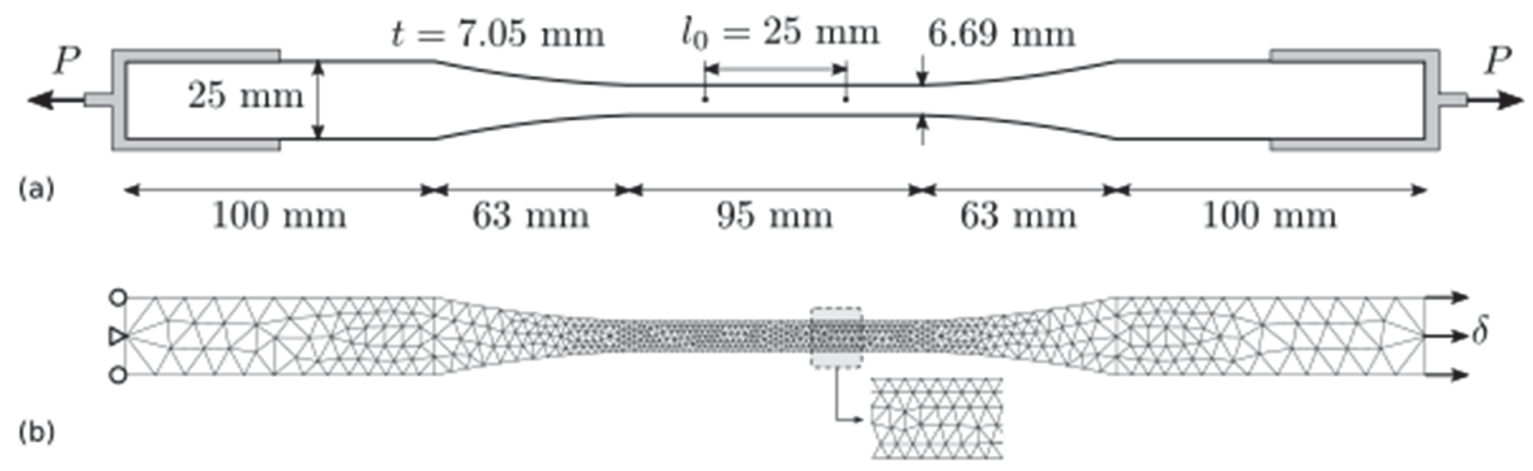

Figure 3: LGB specimen subjected to tensile stress: (a) sketch of the experimental tested specimen, (b) finite element mesh of the numerical simulation, with a detail of the mesh.

\section{Tensile test}

Fig. 3 shows a sketch of the experimental test specimen [4,31] and the numerical specimen with its mesh. Laboratory instrumentation gives us the load $P$ and the relative displacement $\delta$ at the two central points.

The domain is discretized in 1008 triangular elements, reducing the size at the central part of the specimen, where it is presumed to fail. The left border is displacement constraint, and an incremental displacement $\delta$ is imposed to the nodes at the right border. Fig. 4 shows lines of equal displacement at three different load steps. Fig. 5 shows two specimens with different types of cracks. 

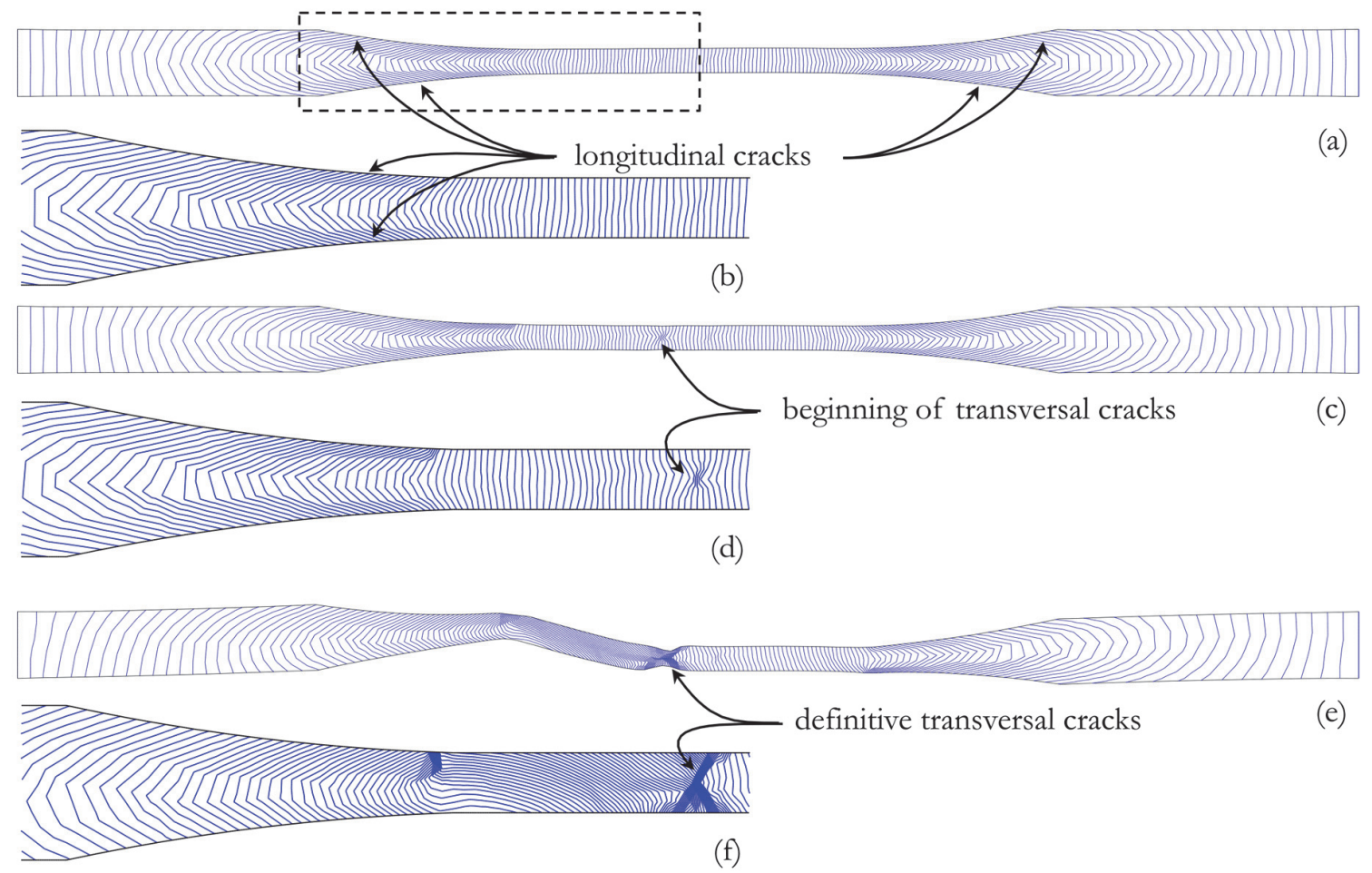

Figure 4: Evolution of iso-displacement contour lines of the tensile test. Displacement concentration at the transition zone of the cross-section, representing longitudinal cracks: (a) in whole specimen and (b) close-up. Displacement concentration at the reduced cross-section, representing beginning of transversal crack: (c) in whole specimen and (d) close-up. Displacement concentration band representing a transverse crack: (e) in whole specimen and (f) close-up.

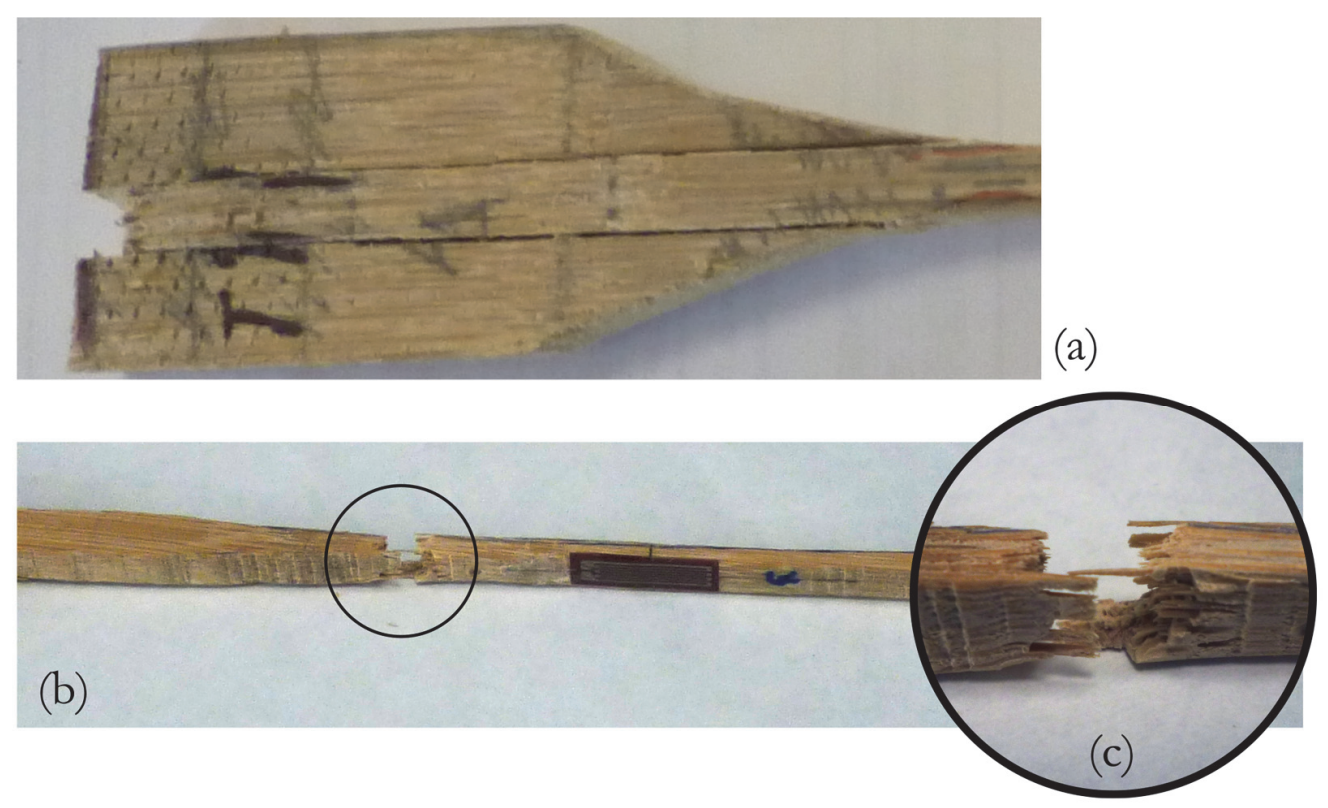

Figure 5: Tensile experimental test: (a) longitudinal cracks at the reduction zone, (b) transverse crack at the reduced zone, and (c) detail of the crack.

\section{Shear test}

Fig. 6 shows the experimental [6] and numerical specimen, with its boundary conditions. The domain is discretized into 1665 elements, and the mesh is refined at the presumed beginning of the crack. Fig. 7 shows the equal displacement lines results compared with experimental findings. 


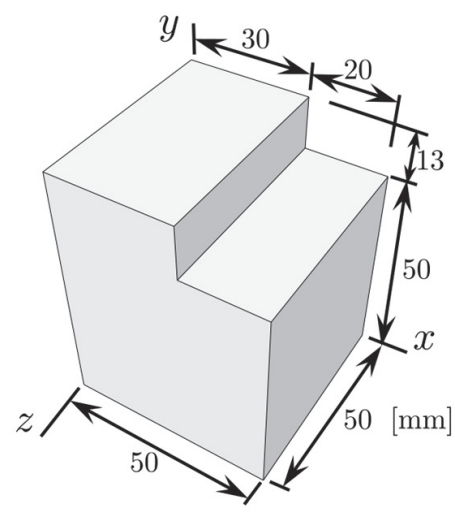

(a)

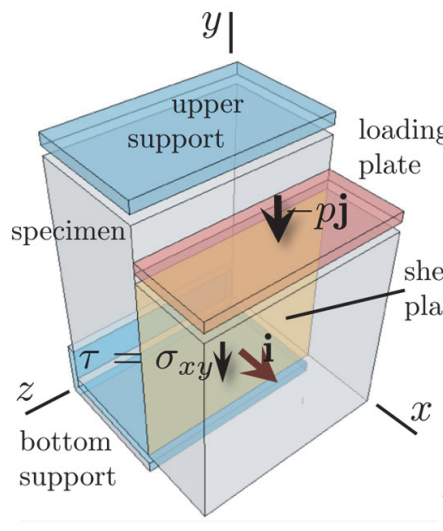

(b)

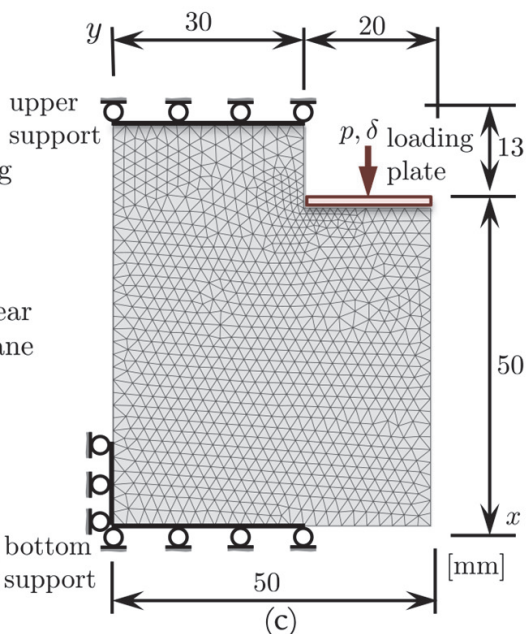

(c)

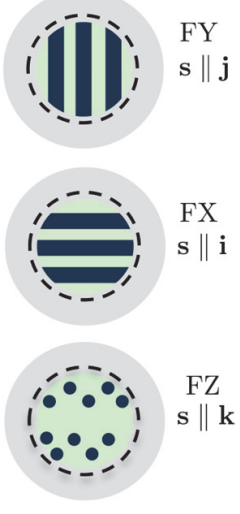

(d)

Figure 6: Test of LGB specimen subjected to shear stress: (a) dimensions of the specimen, (b) constraints and load on the specimen, (c) finite element mesh of the two-dimensional numerical simulation, (d) difference in the orientation of the fibers for each of the 3 configurations of numerical simulations.
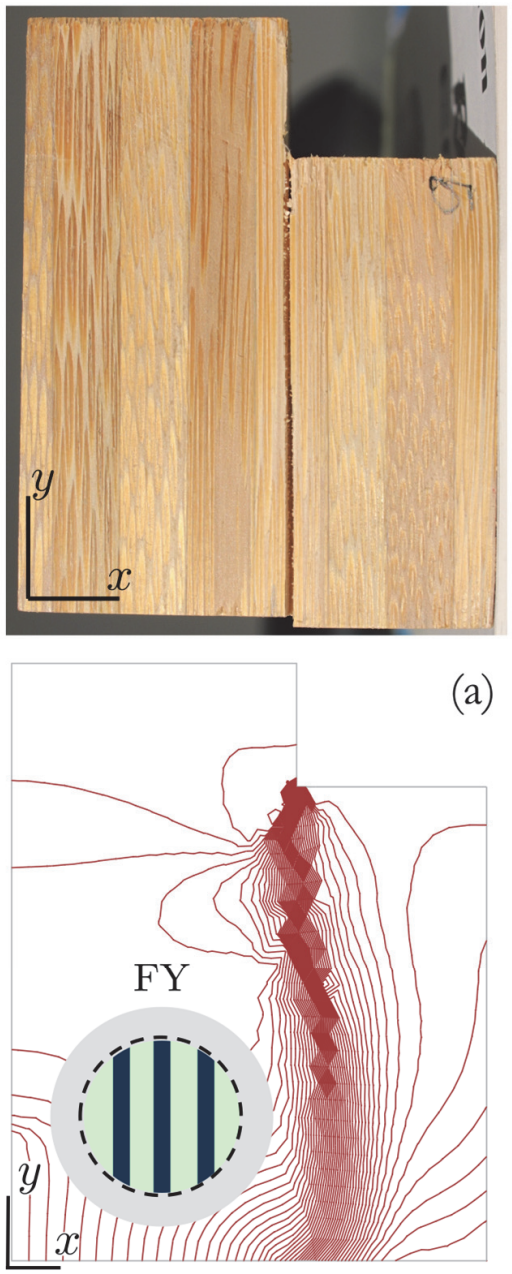

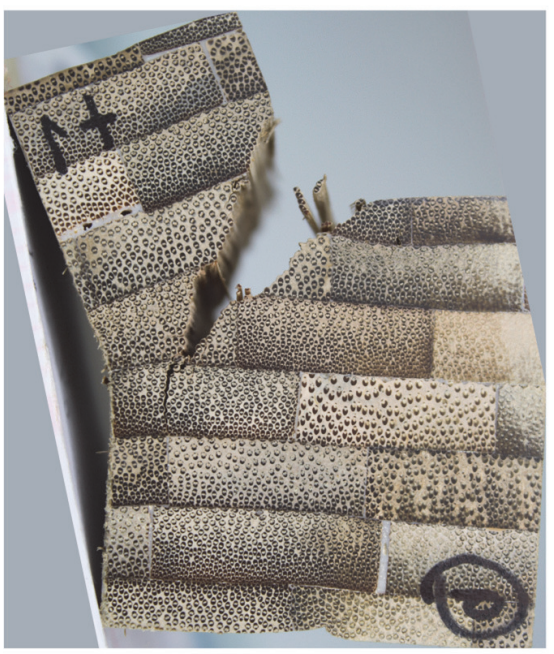

(b)

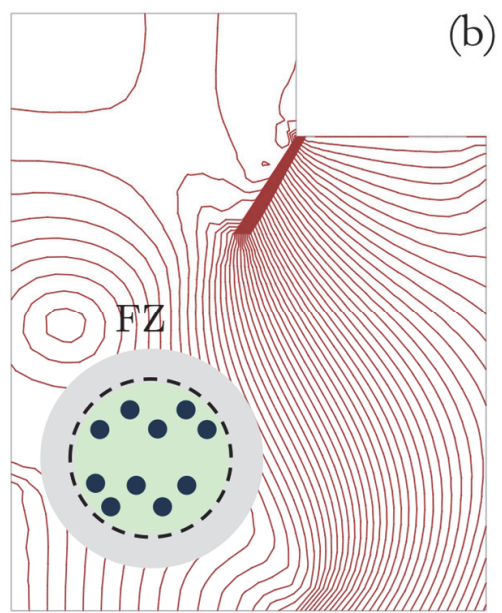

\section{experimental}
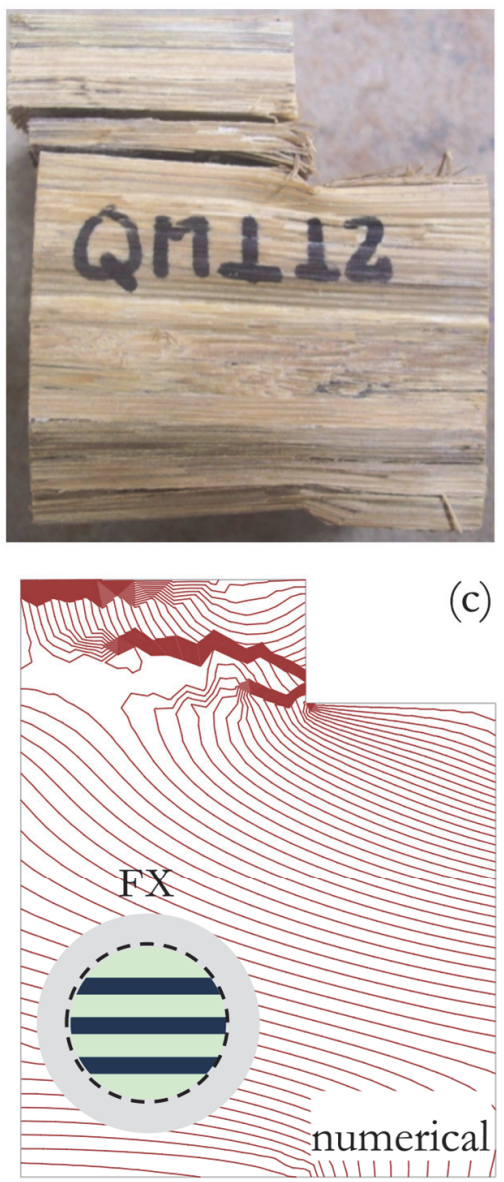

Figure 7: Cracks in the experimental test and the corresponding iso-displacement contour lines in the numerical simulation of LGB specimen subjected to shear stress: (a) FY-fiber direction, (b) FZ-fiber direction and (c) FX-fiber direction. 


\section{CONCLUSIONS}

$\mathrm{T}$

he numerical constitutive model proposed in this work represents correctly the crack pattern of LGB specimen subjected to a static load, which produce tensile and shear stress. The numerical model is robust enough to detect the different failure modes according to different fiber orientations in shear tests.

Tensile tests show that two different crack patterns are possible: longitudinal crack at transition zone of the cross-section and transverse crack in reduced cross-section. The model showed that both types of failure are always present, but they occur at different times. In the zone of reduction of the specimen, a concentration of stresses in the early stages of the test is presented, which implies a possible failure by shear in this region. Subsequently, if the material has enough shear strength to avoid this type of fracture, the appearance of a failure by traction in the reduced area will be seen. In essence, traction failure can only be obtained if it is guaranteed that the specimen has sufficient shear strength to avoid failure in the area of cross-sectional area reduction.

\section{REFERENCES}

[1] Londoño, X. (2003).Recurso sostenible de incunable valor. Guadua: arquitectura y diseño, Bogotá, Colombia, Villegas editores, pp. 22-39.

[2] López, L.F., Silva, M.F. (2000).Comportamiento sismorresistente de estructuras en bahareque. Universidad Nacional de Colombia, Manizales, 2000.

[3] Ghavami, K., Rodríguez, C.S., Paciornik, S. (2003). Bamboo: Functionally Graded Composite Material, Asian J. Civ. Eng. (Building Housing), 4(1), pp. 1-10.

[4] López, L.F., Correal, J.F. (2009). Estudio exploratorio de los laminados de bambú Guadua angustifolia como material estructural, Maderas Cienc. y Tecnol., 11(3), pp. 171-82.

[5] Takeuchi, C.P., Rivera, J.F., Rusinque, M. (2009).Structural Behaviour of Braced Guadua Frames. Non-Conventional Materials and Technologies (NOCMAT), Bath, UK, pp. 6-9.

[6] Takeuchi, C.P. (2013).Caracterización mecánca del bambú guadua laminado para uso estructural. Universidad Nacional de Colombia, 2013.

[7] Liese, W. (1998). The Anatomy of Bamboo Culms, International Network for Bamboo and Rattan (INBAR).

[8] Liese, W. (1992).The Structure of Bamboo in Relation to its Properties and Utilization. Bamboo and its Use: International Symposium on Industrial Use of Bamboo, Beijing, China, International Tropical Timber Organization and Chinese Academy of Forestry, pp. 95-100.

[9] Liese, W. (1985). Bamboos - Biology, Silvics, Properties, Utilization, Germany, Deutsche Gesellschaft fur Technische Zusammenarbeit (GTZ).

[10] Gritsch, C.S., Abranson, K., Vélez, G.C.C., Rashid, M., Murphy, R.J., Camargo, J.C. (2004). Anatomical culm analysis of Guadua angustifolia in relation to age, site, and physico-mechanical properties. Simposio internacional Guadua, Pereira, Colombia.

[11] Silva, E.C.N., Walters, M.C., Paulino, G.H. (2006). Modeling bamboo as a functionally graded material: lessons for the analysis of affordable materials, J. Mater. Sci., 41(21), pp. 6991-7004, DOI: 10.1007/s10853-006-0232-3.

[12] Moreno, L.E., Trujillo, E.E., Osorio, L.R. (2007). Estudio de las características físicas de haces de fibra de Guadua angustifolia, Sci. Tech. Año XIII, 34, pp. 613-7.

[13] Osorio, J.A., Vélez, J.M., Ciro, H.J. (2007). Estructura interna de la Guadua y su incidencia en las propiedades mecánicas, Dyna, 74(153), pp. 81-94.

[14] Estrada, M. (2017).Modelo numérico micromecánico del proceso de fractura de estructuras fabricadas con bambú Guadua angustifolia. Universidad Nacional de Colombia.

[15] Dvorak, G.J., Bahei-El-Din, Y.A. (1982). Plasticity Analysis of Fibrous Composites, J. Appl. Mech., 49(2), pp. 327.

[16] Simó, J., Ju, J. (1987). Strain and stress based continuum damage models. I. Formulation, Int. J. Solid Struct., 23, pp. 821-840.

[17] Simo, J.C., Hughes, T.J.R. (1998). Computational Inelasticity, Springer.

[18] Estrada, M., Linero, D.L., Ramírez, F. (2013). Constitutive relationship of the fiber cluster of bamboo Guadua angustifolia, determined by means of a Weibull probability function and a model of progressive failure, Mech. Mater., 63, pp. 12-20, DOI: 10.1016/j.mechmat.2013.04.007.

[19] Oliver, J., Huespe, A.E., Linero, D.L. (2005).Strong Discontinuity Approach to Fracture of Composite Materials. 11th 
International Conference on Fracture, Turin (Italia).

[20] Oliver, J., Linero, D.L., Huespe, A.E., Manzoli, O. (2008). Two-dimensional modeling of material failure in reinforced concrete by means of a continuum strong discontinuity approach, Comput. Methods Appl. Mech. Eng., 197(5), pp. 332-348, DOI: 10.1016/j.cma.2007.05.017.

[21] Baley, C. (2002). Analysis of the flax fibres tensile behaviour and analysis of the tensile stiffness increase, Compos. Part A Appl. Sci. Manuf., 33(7), pp. 939-948, DOI: 10.1016/S1359-835X(02)00040-4.

[22] Biagiotti, J., Fiori, S., Torre, L., López, M.A., Kenny, J.M. (2004). Mechanical properties of polypropylene matrix composites reinforced with natural fibers: a statistical approach, Mater. Eng., 25(1), pp. 26-36.

[23] Andersons, J., Sparnins, E., Joffe, R., Wallstrom, L. (2005). Strength distribution of elementary flax fibres, Compos. Sci. Technol., 65(3), pp. 693-702, DOI: 10.1016/j.compscitech.2004.10.001.

[24] Wang, Z., Xia, Y. (1998). Experimental evaluation of the strength distribution of fibers under high strain rates by bimodal Weibull distribution, Compos. Sci. Technol., 57(12), pp. 1599-1607, DOI: 10.1016/S0266-3538(97)00092-4.

[25] Weibull, W. (1939). A statistical theory of the strength of materials, Stockholm, Generalstabens litografiska anstalts förlag.

[26] Oliver, J., Cervera, M., Oller, S., Lubliner, J. (1990).Isotropic Damage Models and Smeared Crack Analysis of Concrete. In: Bicanic, H., (Ed.), SCI-C Computer Aided Analysys and Design of Concrete Structures, Zell am See, Austria, pp. 3195-3220.

[27] Estrada, M. (2010).Extracción y caracterización mecánica de las fibras de bambú (Guadua angustifolia) para su uso potencial como refuerzo de materiales compuestos. Universidad de los Andes.

[28] Shin, F.G., Xian, X.J., Zheng, W.P., Yipp, M.W. (1989). Analyses of the mechanical properties and microstructure of bamboo-epoxy composites, J. Mater. Sci., 24(10), pp. 3483-3490, DOI: 10.1007/BF02385729.

[29] Li, S.H., Zeng, Q.Y., Xiao, Y.L., Fu, S.Y., Zhou, B.L. (1995). Biomimicry of bamboo bast fiber with engineering composite materials, Mater. Sci. Eng. C, 3(2), pp. 125-30.

[30] Barthelat, F., Yin, Z., Buehler, M.J. (2016). Structure and mechanics of interfaces in biological materials, Nat. Rev. Mater., 1(4), DOI: 10.1038/natrevmats.2016.7.

[31] CIMOC. (2010). Validación Tecnológica de los Laminados de Guadua para la Industria de la Construcción, Bogotá, Colombia, Centro de investigaciones en materiales y obras civiles. 